\title{
KITCHIN E O FENÔMENO BANANA
}

Luiza Nana Yoshida

Somente agora, às portas do século XXI, o Japão consegue se desvencilhar da sua imagem de país do exótico e das gueixas, para ser reconhecido como uma nação mundial, participante, lado a lado, com as potências mundiais na tomada das grandes decisões.

Durante longos anos, as suas portas foram fechadas para o Ocidente, e, a abertura iniciada em 1868, com a Restauração Meiji, obrigou o Japão a enfrentar uma corrida desigual com o mundo, para importar e assimilar tudo o que o Ocidente tinha a lhe oferecer, em todos os campos.

No campo da literatura, por exemplo, os escritores japoneses viram-se diante de inúmeras correntes literárias, concomitantemente, o que criou uma espécie de caos de "ismos", em meio ao qual, cada um teve que buscar sua identidade.

Do mesmo modo, o Ocidente demorou a conhecer e a reconhecer os escritores japoneses. Não estaremos longe da realidade, se dissermos que, até 1968, quando Yasunari Kawabata foi laureado com o Prêmio Nobel de Literatura, era mínimo o número de ocidentais capaz de citar o nome de um escritor japonês ou de uma obra japonesa moderna de renome.

Atualmente, muitos escritores consagrados, mas já falecidos, como Sôseki Natsume, Ryûnosuke Akutagawa, Yukio Mishima ou o próprio Kawabata têm seus livros traduzidos em línguas ocidentais. Outros, também renomados e ainda atuantes como Kenzaburô Ôe, Yoshiyuki Junnosuke, Shûsaku Endô também têm sido traduzidos e começam a se estabelecer numa determinada faixa do público ocidental. Mas existe ainda, pela frente, um longo chão a ser percorrido, até que seus nomes não soem tão estranhos ao ouvido ocidental. Talvez com o esforço empreendido pelo Japão, no sentido de se tornar cada vez mais conhecido no Ocidente, dentro de algum tempo, eles deixem de ser apenas escritores japoneses, para se estabelecerem como escritores do mundo. 


\section{Banana Yoshimoto da novíssima geração}

O "fenômeno Banana", como ficou conhecido no Japão, foi um dos grandes fenômenos literários que assolaram o país na década de oitenta, ao lado do "fenômeno Haruki", referente a Haruki Murakami, outro renomado escritor da atualidade.

Filha de Takaakira Yoshimoto, um conceituado crítico, nascida Mahoko Yoshimoto, em 1964, explica que aspirava a carreira literária desde menina e adotou o pseudônimo tão peculiar, Banana, por apreciar a flor da bananeira.

Banana recebeu, em 1988, o prêmio literário Kaien, para novatos, com Kitchin (A Cozinha) e, a outra obra Utakata / Sankuchuari (A Espuma/O Santuário) recebeu a indicação para o Prêmio Akutagawa, também em 1988. Recentemente, Banana teve, concomitantemente, quatro de seus livros incluídos na lista dos dez mais vendidos.

O seu estilo moderno e despretensioso rião deixa de provocar certa polêmica entre os críticos, mas quase todos são unânimes em reconhecer que Banana foi capaz de captar, na medida exata e de maneira lúcida, o feeling da jovem geração japonesa.

Não sabemos afirmar se o "fenômeno Banana" será passageiro ou terá força suficiente para se manter e se estabelecer definitivamente. Só o tempo nos dirá. Estamos somente certas de que Banana vem demonstrando, a cada novo lançamento, que talento e capacidade para a sua definitiva afirmação não Ihe faltam.

\section{Sobre Kitchin, o livro}

O livro Kitchin, lançado em 1988, é, na realidade, composto por três contos: Kitchin (A Cozinha), Mangetsu - Kitchin 2 (Lua Cheia A Cozinha 2) e Mûn raito shadou (Sombras do Luar). Trata-se do livro de estréia de Banana e, os contos, aqui reunidos, foram escritos na época em que ela trabaIhava num salão de chá.

Diz a escritora, no posfácio de Kitchin, que sempre escreveu "no desejo de transmitir somente uma verdade e, que a sua aspiração é continuar a escrever, haja o que houver, até que não queira mais falar sobre isso" O livro Kitchin, continua ela, "é a forma padrão dessa perseverante História"

Ainda segundo suas palavras, "A conquista e o amadurecimento são os registros do espírito individual, são a esperança e a potencialidade na 
sua totalidade" Essa filosofia de vida cristalizada e expressa através de palavras resulta em Kitchin.

\section{Kitchin, o conto}

O conto em questão pode ser resumido da seguinte maneira:

- Eu, Mikage Sakurai, encontra-se completamente só, após a morte de sua avó, sua única família.

- Surge Yũichi Tanabe, conhecido de sua avó e estudante da mesma universidade que freqũenta Mikage, para convidá-la a morar com ele e sua mãe (na realidade, seu pai transformado em mãe).

- Mikage é acolhida com todo o amor, ganha e aceita a nova família, embora consciente de que, um dia, terá que seguir, sozinha, o seu caminho.

\section{O lugar do qual mais gosto, neste mundo, é a cozinha.}

Seja de onde for, seja de que tipo for, sendo uma cozinha, sendo um local onde se prepara a refeição, não me é doloroso.

$\mathrm{Na}$ abertura de Kitchin, Mikage coloca claramente a sua posição: a cozinha, para ela, é o local onde se prepara a refeição e o gostar equivale a não ser penoso.

A cozinha como o local onde se prepara a refeição significa, em termos de cultura, a volta a um tempo passado, levando-se em conta que, numa época de alimentos congelados e pratos prontos, a cozinha transformase, antes, no local onde se come. O que se presencia é a adaptação de Mikage à cultura atual, sem deixar de lado a cultura antiga na qual cresceu, ao ser criada por sua avó. E essa adaptação é encarada de uma maneira racional e sensata, na medida em que é aceita (o lugar onde mais gosto) ponderadamente (não me é penoso).

Cabe lembrar que a cozinha como a concebemos hoje, ou seja, como parte integrante da casa, construída no mesmo nível dos outros aposentos e assoalhada, data de época recente, no Japão. Embora já na era Edo (1603 a 1868) esse tipo de cozinha pudesse ser encontrada, a sua popularização só vai ocorrer após a II Guerra Mundial, quando habitaçōes mais modernas começaram a ser construídas.

Houve uma época em que não existia, praticamente, um espaço denominado "cozinha"; o que havia era o kamado (tipo de fogão a lenha) e o nagashi (a pia antiga) instalados num canto do doma (um espaço não as- 
soalhado, em nível mais baixo que o resto da casa). O doma desempenhava um papel muito importante, pois representava não só o espaço onde se realizavam os afazeres domésticos, mas também era utilizado como o espaço para o próprio trabalho de produção. Era o espaço que não só acomodava a "cozinha" num dos cantos, mas, na zona rural, transformava-se no estábulo e no celeiro e, numa casa comercial, a loja localizava-se no doma.

Curiosamente, o doma era também o único espaço dentro de casa onde se permitia o dosoku (os pés calçados), por tratar-se de um chão não assoalhado. Nos outros aposentos entrava-se descalço ou trocava-se por um calçado apropriado, costume ainda adotado em muitas casas japonesas.

Além do aspecto prático (não precisar tirar os sapatos para entrar em casa, ao chegar de fora), o dosoku parece ter ligação com o trabalho, ou seja, o doma é o espaço onde são realizadas as várias atividades, profissionais ou domésticas: nos dias de chuva ou à noite é aí que os agricultores realizavam suas tarefas e as mulheres cozinhavam. Estar no doma significava estar trabalhando.

Com o passar do tempo, o estábulo e o celeiro ganham espaço próprio, independentes da casa e a cozinha incorpora-se à casa, ganhando também seu próprio espaço. Realiza-se, desse modo, a separação geográfica entre o trabalho de produção e os afazeres domésticos.

O preparo da refeição realizado na cozinha tem sido, desde há muito, uma obrigação exclusiva da mulher. No Japão de hoje, entretanto, o trabaIho na cozinha tornou-se opcional, devido à automação, à venda de pratos prontos e ao sistema de demae (entrega de pratos prontos a domicílio). Desse modo, $o$ ato de cozinhar passa a ser encarado como um hobby, onde cozinhar significa experimentar (preparar e comer) pratos renomados ou exóticos, pelo puro prazer de cozinhar. É o afazer cotidiano e o "comer para nutrir-se" substituídos pela arte culinária e pela gastronomia.

$O$ fato de Mikage trazer a cozinha como o seu lugar preferido tem, provavelmente, estreita ligação com isso. $E$, refletindo-se, mais um pouco, sobre o espaço denominado "cozinha", surgem outros fatores que poderiam fundamentar tal escolha.

As antigas casas do Japão caracterizavam-se por não possuir paredes divisórias fixas entre os vários cômodos. Estes podiam ser divididos por portas corrediças, conforme a necessidade. Por conseguinte, a família compartiIhava, quase que todo o tempo, um mesmo espaço. Com a popularização das construçōes modernas (estilo ocidental), iniciada após a II Guerra, as casas passaram a ter paredes divisórias fixas entre os aposentos o que ocasionou a separação geográfica entre os membros da família, na medida em que surgem os quartos individuais. 
A cozinha, nesse caso, vai funcionar como um espaço comunitário que une toda a familia na hora da refeição. Além do mais, a cozinha é, ainda, o espaço intimamente ligado à figura da mãe, representando, assim, o espaço mais "doméstico" de uma casa. Cabe lembrar que trata-se também do espaço que mantém estreita ligação com todos os sentidos do homem: olfato (cheiro dos alimentos), audição (sons característicos do preparo de uma refeição: cortar, bater, fritar...), gustação (degustar os alimentos), visão (saborear os alimentos com os olhos), tato (calor do fogo, frio da geladeira...) o que a torna completa, no sentido de satisfazer todos os anseios humanos.

Gosto demais, ainda que seja uma cozinha extremamente suja.

Ai, onde, no chão, se espalham pedaços de verdura e tão suja que enegrece a sola do chinelo, é bom que seja exageradamente espaçosa. Ergue-se uma geladeira gigante, em cujo interior enfileiram-se provisões suficientes para passar facilmente um inverno, e eu me encosto nessa porta prateada. Ao levantar casualmente os olhos do fogão todo salpicado de óleo ou da faca com pontos de ferrugem, fora da janela, a estrela brilha solitariamente.

Restamos eu e a cozinha. Acho que é um pensamento, no mínimo, melhor, do que pensar que estou só.

Mikage imagina uma cozinha de proporções gigantescas (exageradamente espaçosa) e com aparelhós também desproporcionais (geladeira gigante). Ela parece se perder nessa imensidão e a sua existência afigura-se minúscula, tal qual a estrela solitária que vê pela janela.

A atração de Mikage por uma cozinha que, enquanto gigantesca parece aumentar a sua solidão, explica-se pela presença de um "viver", sentido nos vestígios aí presentes: os pedaços de verdura caídos no chão, a geladeira abarrotada de comida, o fogão salpicado de óleo...

A sua cozinha, no entanto, encontra-se atualmente, destituída de qualquer presença, explicada pelo fato de encontrar-se só, pois perdera a avó, o único elo familiar e "dona" dessa cozinha.

Os pais de Mikage morreram muito cedo e ela fora criada pelos avós. Ainda criança, perdera o avô. Desde então, a sua família resumia-se na sua avó. Mas ela, que efetivamente fora pai e mãe, acaba também falecendo: espantada!

Há dias atrás, pasmem, a minha avó acabou morrendo. Fiquei

Ao me lembrar, repentinamente, que algo real, denominado familia, foi desaparecendo, um a um com o passar dos anos e, que restei 
aqui, sozinha, tudo à minha frente começa a parecer uma ilusão. É um espanto que eu esteja sozinha no quarto em que me criei, e o tempo continue a fluir normalmente, alheio a tudo que ocorre em volta.

O desaparecimento completo da família, já tão reduzida, é sentido, antes, como um espanto do que como um choque. Perceber que, embora sozinha, não há qualquer alteração no seu espaço e no seu tempo, configurase ainda mais espantoso.

É esse espanto que vai, inicialmente, abrir os olhos de Mikage para a existência de uma dura realidade, que independe de qualquer outra para continuar a existir.

A partir de então, Kitchin vai retratar minuciosa e lucidamente, na dimensão do cotidiano, o processo de maturidade de Mikage que, diante dessa dura realidade, busca, dentro de suas possibilidades, encontrar o seu próprio caminho, ou seja, a sua própria identidade.

Em Kitchin, esse processo vai ser enfocado, principalmente, sob o ponto de vista familiar, trazendo à tona a questão jovem / familia.

Esse problema, entretanto, vai ser abordado não com o tradicional esquema jovem $x$ família, mas através de um esquema que reflete o contexto atual:

jovem $\mathrm{x}$ inexistência da estrutura familiar tradicional

No que se refere à constituição da família nuclear (casal + filho), tanto Mikage como Yûichi são jovens oriundos de famílias (tradicionalmente) incompletas: Mikage fora criada pela avó e Yûichi, pela mãe (que, na realidade, é o seu pai). A inexistência da estrutura familiar tradicional (casal + filho) aparece, desse modo, no caso de Mikage como $\emptyset$ e, no caso de Yûichi, na forma de uma nova estrutura familiar, constituída apenas por um dos cônjuges e o filho.

Note-se que os dois jovens têm, em comum, a falta de vivência numa família nuclear, sendo que Mikage cresceu numa estrutura familiar mais antiga do que a tradicional, a família linear (três gerações), e Yûichi, numa estrutura familiar posterior à tradicional, constituída apenas pelo pai (ou mãe) + filho.

Mikage representa, portanto, a família linear já desaparecida $(=\emptyset)$ e Yûichi, uma constituição familiar moderna que se caracteriza pela ausência de um dos cônjuges. 
O fato de a autora ter estabelecido uma constituição familiar tão peculiar, "mãe" (ou melhor, o pai transvestido de mãe) + filho, ilustra primorosamente a situação da típica família japonesa da atualidade (a sociedade do assalariado) que, embora, formalmente, seja constituída de casal + filho, caracteriza-se, na prática, pela ausência da figura paterna, explicada pelos seguintes fatores:

a) a instituição familiar japonesa que (ainda) encara a educação dos filhos como obrigação exclusiva da mulher, razão pela qual o pai japonês é tão somente o sustentáculo econômico e, espiritualmente, torna-se um pai ausente, de corpo presente;

b) o sistema do tanshin funin (a ida do trabalhador para uma outra localidade, sem a família, a fim de ocupar um posto designado pela empresa), adotado por muitas empresas japonesas, que acaba transformando o pai japonês, num pai ausente, de corpo ausente.

A família constituída por Eriko ("mãe") e Yûichi personifica, ao mesmo tempo, a situação atual da família japonesa (a nulidade do homem enquanto figura paterna) e a situação futura (que existe atualmente como tendência), em que a mãe vai também exercer uma atividade profissional (= econômica) fora do lar (Eriko é dona de um bar gay).

Quando Mikage passa a morar com Yûichi e Eriko, o que se vê, a princípio, é naturalmente o seu total deslumbramento diante de uma constituição familiar tão distante do seu, em todos os aspectos. Com relação à própria moradia, por exemplo, enquanto Mikage e a avó moravam no que os japoneses chamam de apâto (pela descrição do ambiente) que equivale, aproximadamente, ao nosso apartamento mais modesto, de pequeno porte, Yûichi e Eriko residem no manshon, apartamento mais requintado.

Quando levantei os olhos para ver esse prédio que se elevava para o céu, o 10 ${ }^{\circ}$ andar onde ficava o seu apartamento era muito alto e pensei que, certamente, deveria avistar-se um belo panorama noturno.

Percebe-se nessas palavras o distanciamento que há entre Mikage e esse tipo de habitação e, ao mesmo tempo, o velho anseio humano por encontrar algo novo e belo num espaço que Ihe é desconhecido (deveria avistar-se um belo panorama noturno).

(...) tratava-se de um aposento deveras estranho é a primeira impressão do interior do apartamento e, o que se destaca aos olhos de Mikage é um sofá gigante - tipo de sofá que aparece em comerciais de TV, que comportaria uma familia inteira e que combinaria com um cachorro gigante, 
do tipo impossivel de se criar no Japão - a existência de muitas plantas e da cozinha.

A sala, desprovida de móveis e sem tapete, possuía somente as peças representativas de uma sala típica de hoje, no Japão: o sofá e o aparelho de televisão (entenda-se televisor + vídeo).

Esta sala, à moda ocidental, contrasta com a sala, em estilo japonês (washitsu) onde Mikage assistia aos programas de TV com a sua avó, sentada sobre o tatami (tipo de esteira com que se forra o chão das salas em estilo japonês). Não, sem razão, portanto, que o sofá, segundo ela, gigante, tenha chamado a sua atenção e, ao sentar-se nele, tenha experimentado uma sensação de deslumbramento.

A cozinha, apropriadamente bem equipada, possuía todo o necessário para se preparar uma refeição e encanta Mikage: Eu amei demais esta cozinha, logo que a vi. Para Eriko e Yûichi essa cozinha toda equipada não passa de enfeite, ou seja, para eles que representam a familia moderna, a cozinha existe apenas como uma teoria, pois ela representa tão somente o espaço onde se come, enquanto que para Mikage, criada numa cultura mais antiga, a cozinha representa o espaço onde se prepara a comida.

Embora recolhida (segundo suas palavras) por uma família praticamente desconhecida e num espaço tão distinto do seu, Mikage sente-se acolhida e dorme tranqüila:

Eu ri, pois achei engraçado estar enrolada num cobertor e dormir, também esta noite, perto da cozinha. Mas, não existia solidão. Quem sabe, eu estivesse esperando. Quem sabe, eu só estivesse procurando um leito onde pudesse esquecer, por alguns instantes, tudo o que aconteceu até agora e o que acontecerá daqui para a frente. Quando temos alguém do lado não é bom, porque a solidão aumenta. Mas, tendo uma cozinha, havendo plantas, tendo alguém sob o mesmo teto e havendo silêncio... era o máximo. Aqui é o máximo!

Desse modo, inicia-se uma nova etapa na vida de Mikage: a vida de "parasita" no apartamento de Eriko e Yûichi.

O primeiro impacto sofrido por Mikage nessa nova vida é com relação à própria moradia, fato referido anteriormente; depois, com relação aos seus moradores e ao seu estilo de vida.

O encontro com Eriko, por exemplo, constitui-se numa sucessão de espanto e deslumbramento, conforme se vê nos seguintes trechos: 
- uma mulher lindíssima, ofegante, adentrou correndo.

- essa pessoa era realmente bela.

- Mãe, isso? Não conseguia despregar os meus olhos (...)

- Cabelos sedosos, chegando nos ombros, olhos obliquos brilhantes, lábios bem feitos, nariz bem formado (...) não se parecia com um ser humano. Nunca havia visto uma pessoa assim.

- Olhando com atenção, certamente, percebi, sim, detalhes humanos como as rugas, próprias da idade, a dentição levemente irregular. Mesmo assim, ela era irresistivel. Fazia-me querer encontrá-la de novo.

O que se destaca em Eriko é a sua beleza, pairando o ideal e quase distante do humano, pois trata-se de uma beleza "fabricada" através da cirurgia plástica. No caso de Eriko, entretanto, o seu belo rosto não é um produto totalmente remodelado pela cirurgia plástica, visto que, o que ela fez foi acentuar os seus belos traços originais (desde a época em que era homem, possuía um rosto bem formado).

Eriko representa o protótipo de uma época em que a cirurgia plástica não só corrigi ou embeleza fisicamente, mas cria novas funçōes, no caso de Eriko, a de ser mãe. Vive-se atualmente, numa época em que, a concepção encarada antigamente como uma função natural da mulher, dá lugar à idéia da maternidade como algo opcional, graças aos inúmeros métodos anticoncepcionais. A mulher não nasce mãe, por natureza, ela torna-se mãe, por opção. Eriko representa a mãe de uma época em que um filho já pode ser concebido fora do ventre materno (bebê de proveta ou mãe de aluguel). Nesse aspecto, Eriko não deixa de ser realmente a mãe de Yûichi, pois ele é de fato seu filho, que foi gerado no ventre de uma outra mulher (sua esposa, mãe geradora de Yûichi).

Dentro desse ambiente totalmente novo e junto a uma família tão peculiar, constituída por um pai que é mãe + um filho criado por uma mãe que é pai, Mikage vai se permitir, durante algum tempo, levar uma vida descompromissada e ser protegida por esta nova família, a fim de recompor suas forças e poder enfrentar o futuro, agora, sozinha.

Nesse seu refúgio momentâneo, Mikage vai se entrosar perfeitamente nesse novo ambiente e nessa nova família, preenchendo e dominando os espaços até então sem um "dono"· o sofá, onde ela passa a dormir e a cozinha, onde ela passa a praticar os seus dotes culinários. 
Ela acompanha também o ritmo de vida dos Tanabe, criando um equilíbrio ao ritmo desencontrado entre Eriko (ausente durante a noite) e Yûichi (ausente durante o dia), na medida em que Mikage passa a ser a ponte que une o dia e a noite, sendo presença comum nos dois períodos.

Observando e participando da vida estranhamente alegre e tranqüila de Yûichi e Eriko, Mikage espanta-se também com a naturalidade com que "mãe" e filho encaram seus papéis e cultivam essa relação de uma maneira sadia e bem-humorada:

(Yûichi) - E ainda por cima, você percebeu? - Continou ele como se não conseguisse conter o riso - Ela é homem, sabe? (...)

(Mikage) - Mas. - Fiquei boquiaberta. - Você dizia minha mãe, minha mãe!

(Yûichi) - Mas, no seu caso, você a chamaria de papai? - Disse ele calmamente.

(Eriko) - Sabe, ele tem várias falhas, pois não me dediquei inteiramente ao seu desenvolvimento.

(Mikage) - Falhas?

Eu sorri.

(Eriko) - Sim. - Disse ela com sorriso de mãe. - Seus sentimentos são desordenados, a sua relação com as pessoas é estranhamente fria, há muitas imperfeições... Eu queria que crescesse bom, sabe, somente nesse aspecto eu me empenhei desesperadamente. Ele é um rapaz bom, sabe?

(Eriko trazendo para casa uma centrífuga)

(Eriko) - Pensei em tornar a minha pele mais bonita, tomando suco natural - Disse Eriko alegre e animadamente.

(Yûichi) - Com essa idade é inútil.

Disse Yûichi, lendo o manual de instruções.

Além disso, Mikage identifica-se com Yûichi no que concerne a uma inexplicável melancolia que os acompanha, embora tenham crescido cercados de amor. Uma melancolia nascida, talvez, do fato de os dois possuírem 
apenas uma "única família" e terem aprendido a sentir, desde cedo, o medo de perdê-la, além da existência de uma firme consciência de que certamente, algum dia, terão que caminhar por si só. Ou ainda, surgida do vazio in . plicável, deixado pela ausência da figura materna, pois ambos conhecem apenas a figura substitutiva da mãe, a avó, no caso de Milkage e o pai, no caso de Yûichi. Tanto Mikage como Yûichi são jovens nascidos e criados numa época em que, como nos referimos anteriormente, a concepção torna-se um ato opcional e não, natural, e ocorre a ruptura entre o ventre materno e a criança, na medida em que o bebê passa a ser concebido fora do ventre materno. Mas são também jovens que sonham, de certa maneira, com a volta a esse ventre materno e o calor de uma animada reunião familiar dos velhos tempos:

(Mikage referindo-se ao seu antigo namorado)

Ele era o filho mais velho de uma familia numerosa e a indefinivel alegria que ele, inconscientemente, trazia de sua casa, reconfortava-me muito.

Esse sentimento de busca ao calor familiar juntamente com o sentimento de uma perda irreversivel reflete-se claramente na cena do ônibus, onde uma senhora tenta agradar uma garotinha, provavelmente sua neta, utilizando-se de todos os artifícios, sem sucesso. A garotinha, muito aborrecida, só esboça um sorriso, quando a avó lhe pergunta se quer ir acordar a mãe que está cochilando num dos assentos traseiros. As palavras carinhosas da avó e a graciosidade da garotinha ao soriir suscitam em Mikage o desejo de fazer parte dessa cena, mas, ao mesmo tempo, fazem crescer dentro dela uma verdade que a sufoca: para ela, nunca mais.

Ao dar-se conta, o seu sentimento interior se exteriorizava sob forma de lágrimas intermináveis. Lágrimas que fluíam sem cessar, carregando consigo inúmeras emoções inexplicáveis. Lágrimas que eram também a concretização de um desabafo, o primeiro, desde a morte de sua avó. $O$ desabafo que mostraria a Mikage contra o que deveria se defrontar daqui para a frente, já que mesmo isso mantinha-se indefinido até entāo. Agora, Mikage sabia contra o que e como se armar. A casa dos Tanabe seria o ponto de partida para uma interminável jornada, uma área de descanso, onde Mikage tomaria fôlego e munir-se-ia de força e coragem para continuar a sua luta.

Mesmo aqui, não posso permanecer para sempre (...)

Será que, algum dia, irei me recordar, com saudades, daqui? nha?

Ou ainda, será que voltarei, algum dia, a estar na mesma cozi- 
Mas, no momento, estou junto a esta competente mãe e aquele rapaz de olhos bondosos. Isso é tudo.

Crescer mais e mais, passar por várias experiências e descer para o fundo inúmeras vezes. Sofrer inúmeras vezes e inúmeras vezes retornar. Não serei derrotada. Não esmorecerei.

A cozinha dos sonhos.

Eu a terei, provavelmente, muitas e muitas. Dentro do meu coração ou de fato. Ou durante uma jornada. Em todos os lugares em que eu viver, eu terei, muitas, com certeza - sozinha, com muitas pessoas, a dois. 